\title{
Signs and sources of stress among students of Medical Sciences
}

\author{
Yektatalab, $S{ }^{1}$, Soleimani, $S^{2}{ }^{2}$
}

\begin{abstract}
Introduction: Entrance in to the University could be accompanied by various stressors which affect students' functional activity and leads to lots of mental problems and academic failure. The present study aimed to identify the signs and sources of stress among students.

Methods: This descriptive-analytical study was conducted on 302 nursing, operating room, anesthesia and medical students at Jahrom University of Medical Sciences selected through purposive sampling. The study data were gathered using two researcher-made questionnaires. The content validity and reliability of the questionnaires was confirmed. The data were entered into the SPSS statistical software (version 16) and analyzed using descriptive statistics, t-test and dun-can test.

Results and Conclusion: The total mean score of stress signs was $13.30( \pm 8.5)$. This measure was obtained as 17.40 in the students above 25 years old, 13.43 in those between 20 and 25 years old and 22.93 in the students below 20 years old; however, the difference was not statistically significant. Female students reported higher signs of stress than did male ones. Also, foreign students reported higher signs of stress than did natives. Besides, the students who paid for education had higher signs of stress compared to those who were educated for free. However, these differences were not statistically significant. The mean score of signs of mental stress was higher than that of physical and social stress. In the physical dimension, palpitation and restlessness; in the social dimension, "not involving in group discussions" and in mental dimension, "inability to be open with others" and "to forgive people" were the most prevalent signs.
\end{abstract}

Keywords: Anxiety, emotional stress, faculty students, health, mental health

\section{Introduction}

Stress is defined as the reaction of one's body and mind to something that causes a change in balance. Stress is a common aspect of many different emotions, such as anxiety, frustration, anger, worry, fear, sadness and despair.

${ }^{1}$ Community Based Psychiatric Care Research Center, Department of Nursing, Shiraz University of Medical Sciences, Shiraz, Iran

${ }^{2}$ Department of Nursing, Shiraz University of Medical Sciences, Shiraz, Iran

Corresponding Author:

Shahrzad Yektatalab

College of Nursing and Midwifery, Shiraz University of Medical Sciences, Shiraz, Iran.

Email: shahrzadyekta@yahoo.com
In the academic scenario, stress has become an inevitable factor in the students' life (Shahmohammadi, 2013). Family problems, lack of interest in the field of study, inappropriate coping strategies, insufficient necessary facilities for students and other difficulties are the factors which can result in high, sometimes extreme level of stress that can eventually be detrimental to the students' health (Lapsley, 1980).

Medical and Para-medical universities have been considered as the most stressful environments and most of the time, have negative effects on the students' educational performance, physical and mental health (Crumpei \& Dafinoiu, 2011; Sheu et al., 2002; Yusoff, 2013). Stress is one of the important factors that affects the individuals' physiological and mental health and is the

DOI: http://doi.org/10.4038/seajme.v12i2.52

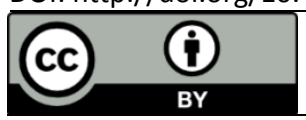

C SEAJME. This is an Open Access article distributed under the terms of the Creative Commons Attribution License (http://creativecommons.org/licenses/by/4.0/), which permits unrestricted use, distribution, and reproduction in any medium, provided the original author and source are credited. 
reason for $50-80 \%$ of diseases (Long et al., 1993).

The hospital is also one of the most stressful environments (Barry, 1989). The tension in these places not only causes academic failure, but also affects student's personality resulting in their inappropriate behavior. Identifying sources of stress helps to reduce them. Another way to eradicate stress is raising the students' awareness to increase their ability to cope with different situations and provide a suitable environment to learn and decrease the signs of stress (Arriner, 1992).

Up to now, many studies have evaluated stress among students. For instance, Sheu (2002) evaluated stress among 561 nursing students in Taiwan and tried to find out how it affected them physically and mentally in their first clinical experience. The results indicated that the sources of stress were mostly lack of enough information about their field of study and lack of autonomy to plan for taking care of patients. Socio-behavioral reaction was the most common reaction to stress.

Another study was performed on Malaysian students and revealed that $41.9 \%$ of medical students had or were suspected to be diagnosed with a mental disorder. Overall, evidence has shown that nursing and midwifery students experience a lot of stress during their education (Sherina et al., 2004).

Gurbind-Kaur et al. (2011) indicated that students' stress was associated with educational (not being satisfied with the field of study, inconsistency between the theoretical and practical training, ineffective way of study, and loads of assignments), clinical (difficulty in taking care of the infectious patients and communicational problems with nurses and instructors) and individual-social factors (coping with new environment, professional future and getting away from family).

Esfandiyari (2001) evaluated the sources of stress and their relationship with public health in medical students in 1999. In that study, 340 students were randomly selected and filled out the source of stress and public health questionnaire. Concerning mental health, the results revealed no statistically significant differences between male and female students, married and single students, native and foreign students, the students who paid for education and those who studied for free, as well as among the students who studied in different fields of education and those who had entered the university in different years. However, statistically significant differences were observed between male and female students, as well as among the students who studied in different fields of education and those who had entered the university in different years regarding the source of stress. Overall, the most important sources of stress were worrying about family's health and one's future occupation.

Considering the mental and spiritual health of students who comprise the largest part of the population in the country, it is important to take serious actions towards this situation, because excessive stress could lead to psychological problems, such as depression and anxiety. Moreover, students play critical roles in building the nation and improving the growth of the economy.

Various studies around the world have emphasized that the students studying in medical fields experience higher stress levels (Sharifirad et al., 2012; Al-Dubai et al., 2011; Yusoff et al., 2013).

However, few studies have been carried out on this topic in Iran, especially on populations in smaller cities. Hence, stress intervention programs should be designed to address stress among college students. In order to design an effective intervention, first the stressors which are specific to college students must be determined. Therefore, the current study aims to determine the signs and sources of stress in nursing, medical, operating room and anesthesia students in Jahrom University of Medical Sciences, Fars Province, Southern Iran.

\section{Methods}

This descriptive analytical study was conducted on 302 nursing, operating room, anesthesia and medical students at Jahrom University of Medical Sciences who were selected through purposive sampling. The institutional Ethics Committee approved the study. Additionally, written informed consent for taking part in the study was obtained from all participants. To ensure anonymity, no questions about the names of students or institutions were included in the questionnaire. All the students of Jahrom University of Medical Sciences participated in this study. The researchers made sure that none of the participants had to take any examinations in the month following the study. 
The nature and purpose of the study was explained for the students and written permission was taken. The study data was collected using two researcher-made questionnaires. The first one covered the demographic data and 59 questions which assessed the signs of physical, social and mental stress.

The questionnaire is scored based on a 4point response scale: "almost never," "sometimes," "often," and "almost always". Each scale consists of 59 items or statements which describe student's common signs of stress. The total scores for signs of stress ranged between 0 and 177 . In this study, the stress signs were divided into Physical (28 questions), Social (15 questions) and Mental signs (16 questions). The scores of Physical, Social and Mental signs of stress ranged between 0-84, 0-45 and 0-48 respectively.

The second questionnaire included 30 questions about the sources of stress. The questionnaire was scored based on a 4-point response scale: "mild," "moderate," "high" and "very high". The reliability of this questionnaire was assessed using the test-retest method and confirmed by Cronbach's alpha $=0.76$.

The content validity of the questionnaires was confirmed by the psychologists and psychiatrists of Shiraz University of Medical
Sciences. The principal investigator was present while the students completed the questionnaires. Absolute privacy and a mental comfort zone were maintained for each student while answering the questionnaires. The data was entered into the SPSS statistical software (version 16) and analyzed using descriptive statistics, t-test and dun-can test.

\section{Results}

Out of the total of 302 students, 298 ones were enrolled into the study. The participants included 145 nursing students, 109 medical students, 22 operating room students and 22 anesthesia students.

According to the results, $27 \%$ of the students were male and $73 \%$ were female. $6.6 \%$ of the participants were married, while $93.4 \%$ were single. Regarding the year of study, $27.9 \%$ of the participants were freshman, $18.6 \%$ were sophomore, $16.6 \%$ were junior, $17.3 \%$ were senior, $5.3 \%$ were 5 th year, $9.6 \%$ were 6 th year and $4.7 \%$ were 7 th year students. The total mean score of stress signs was $13.30( \pm 8.5)$. Additionally, this measure was obtained as 12.59 in male participants compared to 13.66 in female respondents. The results demonstrated no significant association between stress and gender. Table 1 shows the most prevalent statements determining the signs of stress among the students.

Table1: Distribution of stress signs reported by the students

\begin{tabular}{lcc}
\hline \multicolumn{1}{c}{ Signs of Stress } & Frequency & Percentage (\%) \\
\hline I sometimes suffer from palpitation & 104 & $34.6 \%$ \\
I am restless & 114 & $37.9 \%$ \\
I am unsociable & 88 & $29.2 \%$ \\
I suffer from loneliness & 106 & $35.2 \%$ \\
I do not know my neighbors & 140 & $46.5 \%$ \\
I go out with my family once in a blue & 101 & $33.6 \%$ \\
I feel vein & 60 & $19.9 \%$ \\
I need to express myself & 115 & $38.2 \%$ \\
I cannot be open with others & 157 & $52.2 \%$ \\
I hardly ever forgive people & 180 & $59.8 \%$ \\
I am not optimistic very often & 83 & $27.6 \%$ \\
I am suspicious about what I am doing & 135 & $44.9 \%$ \\
I do not express my personal ideas & 103 & $34.2 \%$ \\
I suspect my abilities to be successful & 135 & $44.9 \%$ \\
\hline
\end{tabular}

In this study, the stress signs were divided into physical (28 questions), social (15 questions) and mental signs (16 questions). The mean scores of physical, social and mental signs of stress were $4.8( \pm 3.5), 3.6( \pm 0.5)$ and $4.9( \pm 3.5)$, respectively. According to Table 2, the mean scores of physical and social signs of stress were higher in males, while that of mental 
signs of stress was higher among females. The mean score of stress signs was 17.40 in the students above 25 years old, 13.43 in those between 20 and 25 years old and 22.93 in the students below 20 years old.

Table 2: Mean score of signs of stress in female and male students

\begin{tabular}{lccccc}
\hline \multirow{2}{*}{ Signs of stress } & \multicolumn{2}{c}{ Female } & \multicolumn{2}{c}{ Male } & P Value \\
\cline { 2 - 5 } & Mean & SD & Mean & SD & T-Test \\
\hline Physical signs of stress & 4.9 & 3.5 & 4.4 & 3.7 & 0.331 \\
Social signs of stress & 3.5 & 2.4 & 3.7 & 2.7 & 0.561 \\
Mental signs of stress & 5.2 & 3.5 & 4.3 & 3.6 & 0.05 \\
\hline
\end{tabular}

Moreover, the mean score of the physical signs of stress was $(5.65 \pm 4)$ in married students compared to $(4.8 \pm 3.5)$ in single ones. However, the mean score of social signs of stress was similar in married and single students (3.6 \pm 2.5$)$. Besides, the mean score of the mental signs of stress was $(4.45 \pm 3.8)$ in married students and $(5 \pm 3.5)$ in single ones. Additionally, the mean score of the physical signs of stress was $(5.58 \pm 4)$ and $(4.6 \pm 3.4)$ in native and foreign students, respectively.

Nevertheless, no significant difference was found among these students regarding the mean score of the social signs of stress $3.6( \pm 2.5)$. In addition, the mean score of the mental signs of stress was $5.5( \pm 3.7)$ in native students compared to $4.8( \pm 3.5)$ in non-native ones. As a whole, the overall score of stress signs was $13.36( \pm 8.5)$ in married students and $13.75( \pm 9.6)$ in single ones. Besides, the total score of stress signs was $12.1( \pm 8.2)$ and $13.7( \pm 8.6)$ in native and foreign students, respectively. In addition, the total score of stress signs was $13.3( \pm 8.3)$ in the students who were educated for free and 14.53( \pm 9.4$)$ in those who had to pay for their education. Table 3 shows distribution of sources of stress. The results showed that the main stressors were worries about family's health, future occupation, behavior of university authorities, discriminating the students Overcrowding in dormitories and Being far away from family (Table 3 ).

Table3: distribution of source of stress

\begin{tabular}{lccc}
\hline \multicolumn{1}{c}{ Stressors } & \multicolumn{3}{c}{ Distribution } \\
\cline { 2 - 4 } & Average & High & Very High \\
\hline Worries about family's health & 26.9 & 22.6 & 23.9 \\
Worries about future occupation & 22.6 & 26.9 & 16.3 \\
Inappropriate behavior of university authorities & 25.2 & 15.9 & 12.3 \\
Discriminating the students & 21.3 & 21.6 & 14.6 \\
Overcrowding in dormitories & 17.3 & 11.00 & 14.00 \\
Being faraway from family & 20.6 & 17.3 & 17.9 \\
\hline
\end{tabular}

\section{Discussion}

This study attempted to investigate the signs and sources of stress among the students at Jahrom University of Medical Sciences, Iran. Stress is an important problem faced by medical and Para-medical students during their years of study. In the current study, the mean score of mental stress signs was higher than that of the physical and social ones as a whole. In addition, the mean score of the social signs of stress was higher among the male students, while the mean score of the mental signs of stress was higher among female ones. A similar trend was also observed in the studies conducted by Yamamoto et al., (2009), Hosseini et al., (2013) and Esfandyari (2001).This might be because of sexuality and the fact that females are more vulnerable than males. Also, they are more dependent on their families and being far away from them could culminate in coping problems for them.

In this study, the total score of stress signs was higher in the single students compared to 
the married ones, in the foreign students compared to the native ones and in the students who paid for education compared to those who did not; however, the differences were not statistically significant. These findings are consistent with those of the studies by Lama et al., (2010), Gall (2000) and Esfandyari (2001). This may be due to the fact that living with family and receiving their support, could help the students to cope better with stress (Dennis et al., 2005). Furthermore, the conditions of hostels and dormitories might be unsatisfactory, leading to higher stress among the students living there.

Researchers believe that, considering the importance of physical and mental health of students, it is necessary to provide them with a healthy mindset and positive coping strategies. The findings of the current study showed that the score of stress signs was higher among the nursing and anesthesia students compared to the medical and operating room ones. These results are in agreement with the studies conducted by Guthrie et al., (1995) and Esfandyari (2001). The relationship between years of study and level of stress is important. College students, especially freshmen are particularly prone to stress due to the transitional nature of college life. They must adjust to being away from home for the first time, maintain a high level of academic achievements and adjust to a new social environment. Furthermore, an obviously high level of stress has been noticed among students before they enter the clinical environment (Taramsari et al., 2012).

In contrast, one study conducted on nursing students in Australia indicated that freshmen experienced lower stress levels in comparison to other students in different years of study (Rutt, 2002). Anxiety is a reaction to stress and shows feeling of insecurity and fear when being faced with unknown factors. Communicational problems which lead to mental disorders, sadness and eventually feeling of loneliness could play an important role in creating anxiety among students. Planning for group activity in educational environments and providing communication skill workshops for students could be beneficial in decreasing stress and anxiety (Abazary et al., 2004).

Mirzaee et al., (2010) performed a study to evaluate the perceived stress among nursing students. The results of that study indicated that the highest scores of perceived stress were related to lack of facilities, discrimination among students, instructors' high expectations, taking care of patients of different sexes, students' inadequate clinical knowledge, ineffective relationship between students and instructors, physicians' inadequate care for patients, contradictory guidelines and not working scientifically in the clinical environment.

Another study demonstrated that the sources of stress were mostly intrapersonal. Other sources which can cause stress include change in sleeping habits, having little time for leisure, change in eating habits, increase of workload and having new responsibilities (Sani et al., 2012). In the present study, the most common physical signs of stress among the students were palpitation and restlessness. In the social dimension, not attending group discussions was the most common stress sign. Finally, the inability to be open with others and to forgive people was the most common sign in the mental dimension.

In general, eliminating the stressors can be effective in decreasing the negative effects of stress. This study indicated that the external sources of stress were more important compared to the internal ones. In comparison to other students, the students in clinical fields experience higher levels of stress due more contact with stressful events, such as working in hospital and having problems with the other staff and their instructor. These findings are in line with those of other studies conducted on the issue (Mirzaee et al., 2010; Sani et al., 2012; Soliman, 2013).

\section{Conclusion}

Given the detrimental effects of stress on students' health and academic performance, college administrators should consider incorporating stress management training in orientation activities. In this way, at least the most common sources of stress could be discussed with the incoming freshmen. Furthermore, students should be informed about the campus resources available to help them regarding the stress resources. A better approach may be the use of a stress management workshop, specifically geared to the stressors encountered by college students. Certainly, stress in the college setting cannot be eliminated; therefore, we can and should do a better job preparing our students to manage this problem. Some researchers have tried and found useful programs, such as exercise, relaxation, cognitive control, time management, training exam skills and training 
communication skills, especially designed for lessening stress among medical students (Johnson et al., 2009).

The present study had some limitations. This study was based on the results of a selfadministered questionnaire; hence, reporting bias could not be totally eliminated. In addition, there was limited geographical coverage since the study was conducted in a single urban area. Confounding factors, such as the participants' current emotional state or personality might have been present as well. Other study limitations included its crosssectional design and the fact that it was entirely based on the students' responses. Finally, the conclusions were drawn from the experiences of the students of one university and consequently, may not be applicable to those of other universities.

\section{Acknowledgments}

The authors would like to thank all the students as well as the management of Jahrom University of Medical Sciences for their cooperation in this study. They are also grateful for Ms. A. Keivanshekouh at the Research Improvement Center of Shiraz University of Medical Sciences for improving the use of English in the manuscript. We also thank the authorities of Shiraz University of Medical Sciences for their support.

\section{Conflicting Interests}

The Authors declare no conflicts of interest.

\section{References}

Abazary, F., Abbaszadeh, A. \& Arab, M. (2004) A Study on Level and Sources of Stress in Nursing Students, Strides in Development of Medical Education, 1, 1, pp. 23-31.

Al-Dubai, S.A.R., Al-Naggar, R.A., Alshagga, M.A. \& Rampal, K.G. (2011) Stress and coping strategies of students in a medical faculty in Malaysia, Malaysian Journal of Medical Sciences, 18, 3, pp. 57-64.

Al-Qaisy, L.M. (2010) Adjustment of College Freshman: The Importance of Gender and the Place of Residence, International journal of Psychological Studies, 2, 1, pp. 142-150.

Arriner T.A. (1992) Guide to nursing management, St Lovis Mosby year book, Inc.

Barry, P.D. (1989) Psychosocial nursing assessment and intervention: Care of the physically ill person, Lippincott Williams \& Wilkins.
Crumpei, I. \& Dafinoiu, I. (2012) Secondary traumatic stress in medical students, ProcediaSocial and Behavioral Sciences, 46, 1, pp. 1465-1469.

Dennis, J.M., Phinney, J.S. \& Chuateco, L.I. (2005) The Role of Motivation, Parental Support, and Peer Support in the Academic Success of Ethnic Minority First-Generation College Students, Journal of College Student Development, 46, 3, pp. 223-236.

Esfandyari, G. (2001) Stress Factors and their Relation with General Health in Students of Kurdistan University of Medical Sciences in Year 1999, Scientific Journal of Kurdistan University of Medical Sciences, 5, 2, pp. 17-21.

Gall, T.L., Evans, D.R. \& Bellerose, S. (2000) Transition to First-year University: Patterns of change in Adjustments across Life Domains and Time, Journal of Social and Clinical Psychology, 19, 4, pp. 544-567.

Gurbinder-Kaur, J.S., Hamidah, H., Blackman, I., Wotton, K. \& Belan, I. (2011) Perceived stress related to nursing education and its influence on nursing students' academic and clinical performance, Medicine and Health, 6, 2, pp. 86-97.

Guthrie, F.A., Black, D. \& Show C.M. (1995) Embarking upon a medical career: psychological morbidity in first year medical students, Medical Education, 25, 5, pp. 337341.

Hosseini, L. \& Khazali, H., (2013) Comparing the Level of Anxiety in Male and Female School Students, Social and Behavioral Sciences, 84, pp. 41-46.

Johnson, C.M., Larson, H.A., Conn, S.R., Estes, L.A. \& Ghibellini, A.B. (2009) The Impacts of Relaxation Techniques on Third Grade Students Self-Perceived Level of Test Anxiety, Paper based on a program presented at the 2009 American Counseling Association Annual Conference and Exposition, March 19-23, Charlotte, North Carolina.

Lapsley, D. (1980) Psychological separation adjustment to college, Counseling psychology, 36, pp. 286-294.

Long, B.C., Phipps, W.J. \& Cassmeryer, V.L. (1993) Medical surgical nursing, a nursing process approach, St. Louis Mosby, pp. 89-105.

Mirzaee, O., Vaghei, S. \& Koushan, M. (2010) The Effects of Communicative Skills on the Perceived Stress of Nursing Students, Journal of Sabzevar Universtiy of Medical Science, 17, 2, pp. 88-95. 
Lo, R. (2002) Longitudinal study of perceived level of stress, Coping and self-esteem of undergraduate nursing students: an Australian case study, Journal of Advanced Nursing, 39, 2, pp. 119-126.

Sani, M., Mahfouz, M.S., Bani, I., Alsomily, A.H., Alagi, D., Alsomily, N.Y., Madkhaly, F.M. Madkhali, R., Hakami, A.A.M., Hakami, A. \& ShaqraaShaabi, A.E.S. (2012) Prevalence of stress among medical students in Jizan University, Kingdom of Saudi Arabia, Gulf Medical Journal, 1, 1, pp. 19-25.

Shahmohammadi, N. (2011) Students coping with stress at high school level particularly at 11 th and 12th grade, Procedia-Social and Behavioral Sciences, 30, 1, pp. 395-401.

Sharifirad, G., Marjani, A., Abdolrahman, C., Mostafa, Q. \& Hossein, S. (2012) Stress among Isfahan medical sciences students, Journal of research in medical sciences: the official journal of Isfahan University of Medical Sciences, 17, 4, pp. 402.

Sherina, M.S., Rampal, L. \& Kaneson, N. (2004) Psychological stress among undergraduate medical students, Medical Journal of Malaysia, 59, 2, pp. 207-211.

Sheu, S., Lin, H.S. \& Hwang, S.L. (2002) Perceived stress and physio-psycho-social status of nursing students during their initial period of clinical practice: the effect of coping behaviors, International Journal of Nursing Studies, 39, 2, pp. $165-175$.
Soliman, M. (2014) Perception of stress and coping strategies by medical students at King Saud University, Riyadh, Saudi Arabia, Journal of Taibah University of Medical Sciences, 9, 1, pp. 30-35.

Taramsari, M.R., Badsar, A., Seyednejadb, R. \& Maafib, A.A. (2012) Assessment of Students' Perceptions of Educational Environment in Clinical Wards of University of Hospitals at an Iranian Medical Sciences University, ProcediaSocial and Behavioral Sciences, 46, pp. 715720.

Yamamoto, K., Okazaki, A. \& Funatsu, M. (2009) The relationship between Premenstrual Symptoms, Menstrual Pain, Irregular Menstrual Cycles, and Psychological Stress among Japanese College Students, Journal of Physiological Antropology, 28, 3, pp. 129-136.

Yusoff, M.S.B. (2014) Intervention on medical student's psychological health: A metaanalysis, Journal of Taibah University of Medical Sciences, 9, 1, pp. 1-13.

Yusoff, M.S.B., Pa, M.N.M., \& Rahim, A.F.A. (2013) Mental health of medical students before and during medical education: A prospective study, Journal of Taibah University of Medical Sciences, 8, 2, pp. 86-92. 